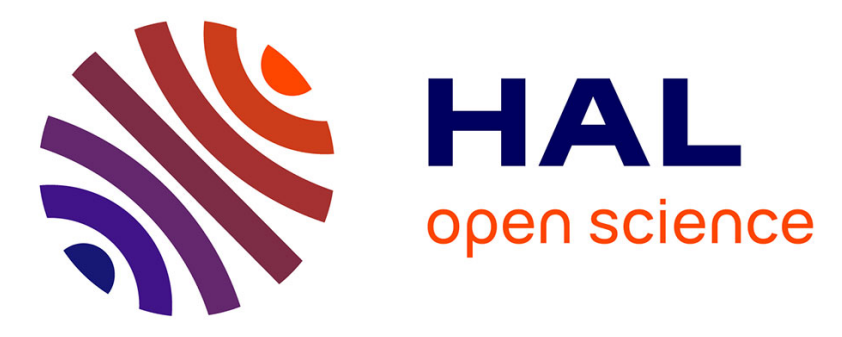

\title{
B/Si multilayers for soft X-ray and extreme ultraviolet optics
}

\author{
Marie-Françoise Ravet, Françoise Bridou, A. Raynal, Bruno Pardo, \\ Jean-Pierre Chauvineau, Jean-Michel André
}

\section{- To cite this version:}

Marie-Françoise Ravet, Françoise Bridou, A. Raynal, Bruno Pardo, Jean-Pierre Chauvineau, et al.. B/Si multilayers for soft X-ray and extreme ultraviolet optics. Journal of Applied Physics, 2001, 89 (2), pp.1145-1150. 10.1063/1.1322590\# . hal-00872668

\section{HAL Id: hal-00872668 \\ https://hal-iogs.archives-ouvertes.fr/hal-00872668}

Submitted on 14 Oct 2013

HAL is a multi-disciplinary open access archive for the deposit and dissemination of scientific research documents, whether they are published or not. The documents may come from teaching and research institutions in France or abroad, or from public or private research centers.
L'archive ouverte pluridisciplinaire HAL, est destinée au dépôt et à la diffusion de documents scientifiques de niveau recherche, publiés ou non, émanant des établissements d'enseignement et de recherche français ou étrangers, des laboratoires publics ou privés. 


\title{
B/Si multilayers for soft $\mathrm{x}$-ray and extreme ultraviolet optics
}

\author{
M. F. Ravet, ${ }^{\text {a) }}$ F. Bridou, A. Raynal, B. Pardo, and J. P. Chauvineau \\ Laboratoire Charles Fabry de l'Institut d'Optique, CNRS-UMR 8501, Bât. 503, \\ Centre Scientifique d'Orsay BP 147, 91403 Orsay Cedex, France \\ J.-M. André \\ Laboratoire de Chimie Physique, CNRS, Université Pierre et Marie Curie, CNRS-UMR 7614, \\ 11 rue Pierre et Marie Curie, 75231 Paris Cedex 05, France
}

(Received 9 December 1999; accepted for publication 9 September 2000)

\begin{abstract}
With the development of x-ray sources, high reflectivity and selectivity multilayers for optics are becoming a field of interest for the spectral region of 13-40 nm. In this article, it is shown from theoretical computations that multilayers made of two light materials such as $\mathrm{B} / \mathrm{Si}$ can be used for these applications. Such multilayers were deposited by electron evaporation. Their physical properties were studied by $\mathrm{x}$-ray reflectometry analyses at two wavelengths: 0.154 and $12.6 \mathrm{~nm}$. The results show that the multilayers are made of dense and pure materials and that the interfacial layer thickness ranges from 0.3 to $0.7 \mathrm{~nm}$. (C) 2001 American Institute of Physics.
\end{abstract}

[DOI: $10.1063 / 1.1322590]$

\section{INTRODUCTION}

In the near future, new $x$-ray sources will dominate the field of soft $x$-ray applications: third generation synchrotron radiation sources, plasma sources, ${ }^{1}$ high-harmonic generation sources, ${ }^{2}$ and x-ray lasers. ${ }^{3,4}$ All these sources are being improved and their use needs the development of optics especially in the low energy range (i.e., below $100 \mathrm{eV}$ ). The x-ray optics required for these applications are, for example, (i) monochromators to select the photon energy, (ii) low absorption beamsplitters for interferometry and x-ray beam monitoring, and (iii) Bragg Fresnel lenses to focalize the x-ray beam. In addition, there is much interest in astrophysics to analyze the spectrum emitted from the solar corona and select emission lines such as: Fe IX $(\lambda=17.1 \mathrm{~nm})$, Fe XII $(\lambda$ $=19.5 \mathrm{~nm}), \mathrm{FeXV}(\lambda=28.4 \mathrm{~nm})$, and He II $(\lambda=30.4 \mathrm{~nm})$. Therefore, the approach of $\mathrm{x}$-ray multilayers is being explored ${ }^{5}$ replacing the classical heavy/light couple of materials by light materials having an optimal contrast of the optic indices for a given wavelength.

All x-ray optics have to be improved in terms of an optimal reflectivity level and/or a good wavelength resolution $(\lambda / \Delta \lambda)$ for a given application at a defined photon energy. They are usually based on multilayers which consist of alternating layers of two materials with a high contrast of their optical indices. ${ }^{6}$ In the past years, there has been an increasing interest in the development of multilayer mirrors which operate at soft $\mathrm{x}$-ray wavelengths, mainly in view of the extreme-ultraviolet (UV) lithography at $13 \mathrm{~nm} .{ }^{7}$ In astrophysics, some mirrors made of materials with low absorption coefficient have been described in the literature, ${ }^{8}$ for applications in the extreme UV (XUV) region.

According to the database of scattering factors given by Henke et al., ${ }^{9}$ we have considered the coupling of boron with

a) Author to whom correspondence should be addressed; electronic mail: marie-francoise.ravet@iota.u-psud.fr silicon to be a good candidate for the 13-40 nm wavelength range. The selectivity of such a structure can be twice as good as the classical $\mathrm{Mo} / \mathrm{Si}$ system, with a potentially improved reflectivity. However, performances of such multilayers depend on deposition conditions of the materials. More particularly, the interfacial roughness and a possible interdiffusion, which are fundamental characteristics of the stacks regarding their optical properties, depend strongly on the deposition technique (magnetron sputtering deposition, $e$-beam evaporation, and ion beam deposition).

Kearney and co-workers ${ }^{10}$ have studied the growth of $\mathrm{Si}$ onto B layers by using the UHV electron beam deposition technique. From AES and XPS experiments, they concluded that a sharp interface was formed between the amorphous $\mathrm{Si}$ and B layers. An upper limit thickness of $0.98 \mathrm{~nm}$ for the interfacial diffusion was measured. Such results are promising for obtaining multilayer mirrors with sharp interfaces and optimal reflectivities for the photon energy range covered by $\mathrm{x}$-ray sources and spectral imaging in astrophysics.

Few experimental results obtained from $\mathrm{B} / \mathrm{Si}$ multilayers have been given in the literature. However, quantitative $\mathrm{x}$-ray analysis of light elements could be achieved with $\mathrm{B} / \mathrm{Si}$ multilayers obtained by ion beam deposition. ${ }^{11}$

The purpose of this article is to give predictive computed results of $\mathrm{B} / \mathrm{Si}$ multilayer reflectivity and to discuss the feasibility of $\mathrm{B} / \mathrm{Si}$ multilayers with well-defined thickness and interfaces, using an electron gun deposition technique combined with in situ x-ray reflectivity measurements. X-ray mirror properties of the multilayers and some leading applications are presented. Actually, the favored goal of the study presented in this article is the beamsplitter application.

\section{THEORETICAL REFLECTIVITY OF B/Si MULTILAYERS}

\section{A. Method of calculation}

We consider a periodic structure consisting of $N$ pairs of alternating layers made of two materials with indices $n_{1}$ and 
$n_{2}$, respectively. If $p$ is the period of the structure, the fraction of the period occupied with the heavy material (higher $Z)$ is $e_{\text {heavy }}$, and the ratio $e_{\text {heavy }} / p$ is $\gamma$.

Reflectivity and wavelength resolution $(\Delta \lambda / \lambda)$ are determined by the thickness of the period $p$, the number $N$ of pairs of layers, the thickness ratio of the two materials, and the material combinations. In order to reach a high reflectivity, the index contrast (both the real and imaginary part) has to be maximized. Moreover, the absorption, which depends on the extinction coefficient, limits the efficiency of the multilayer, and has to be small for the two layers in the period.

Different approaches to calculate the exact reflected intensity like matricial products ${ }^{12}$ or the so-called recursive method starting with the Fresnel equations ${ }^{13,14}$ have been used. The computer program used here works with the recursive method taking into account the roughness of interfaces, according to the model of Névot and Croce ${ }^{15}$ and Névot et al. ${ }^{16}$ This model considers that the weakening of the amplitude wave crossing every interface depends on the roughness by the Debye-Waller (DW) factor

$$
\mathrm{DW}=\exp \left(-8 \pi^{2} k_{1 \perp} k_{2 \perp} \sigma^{2}\right),
$$

where $k_{1 \perp}$ and $k_{2 \perp}$ are the normal components of the wave vector (defined as $1 / \lambda$ ), respectively, above and under the interface. $\sigma$ denotes the root mean squared roughness. For the calculation of the reflectivity versus wavelength $\lambda$, the optical indices are obtained from the atomic scattering factors $f_{1}$ and $f_{2}$ given by the Henke tables. ${ }^{9}$

\section{B. Comparison of reflectivity and selectivity between $\mathrm{Mo} / \mathrm{Si}$ and $\mathrm{B} / \mathrm{Si}$ multilayers}

In order to make XUV mirrors in the 13-40 nm wavelength range, one of the requirements is the high reflectivity. $\mathrm{Mo} / \mathrm{Si}$ is a good candidate in the $12.5-25 \mathrm{~nm}$ field ${ }^{6}$ and has often been used for these applications. Moreover, $\mathrm{Mo} / \mathrm{Si}$ multilayers at $30.4 \mathrm{~nm}$ have a reflectivity power of about $20 \%$ at normal incidence. ${ }^{17}$

The two parts (decrement $\delta$ and absorption $\beta$ ) of the complex indices of Mo, Si and B are shown in Fig. 1. It can be seen, from the comparison of the real part of Mo, B and $\mathrm{Si}$ decrements $(\delta=1-n)$, that in the range of 9-18 nm, the contrast $\Delta \delta$ between Mo and $\mathrm{Si}$ is greater than for B and $\mathrm{Si}$. On the other hand, between 28 and $38 \mathrm{~nm}, \Delta \delta$ is higher for B and $\mathrm{Si}$ and the absorption of $\mathrm{B}$ is also smaller than that of Mo. Despite the fact that B has an atomic mass lower than $\mathrm{Si}$, it represents the heavy layer in the $18-40 \mathrm{~nm}$ wavelength range, because the real decrement and imaginary parts of its complex index are greater than for $\mathrm{Si}$.

Figure 2 shows a comparison between the calculated reflectivity peaks of $\mathrm{Mo} / \mathrm{Si}$ and $\mathrm{B} / \mathrm{Si}$ multilayers around 30.9 $\mathrm{nm}$ in normal incidence. The first curve shows the $\mathrm{Mo} / \mathrm{Si}$ reflectivity obtained from ten periods with an optimized $\gamma$ ratio of 0.24 . For this number of periods, the maximum reflectivity is reached using the recursive and exact method. In order to increase the selectivity of a $\mathrm{B} / \mathrm{Si}$ multilayer, the thickness of the most absorbing material in the bilayer should be reduced. The third curve shows a 20 period $(\mathrm{B} / \mathrm{Si})$
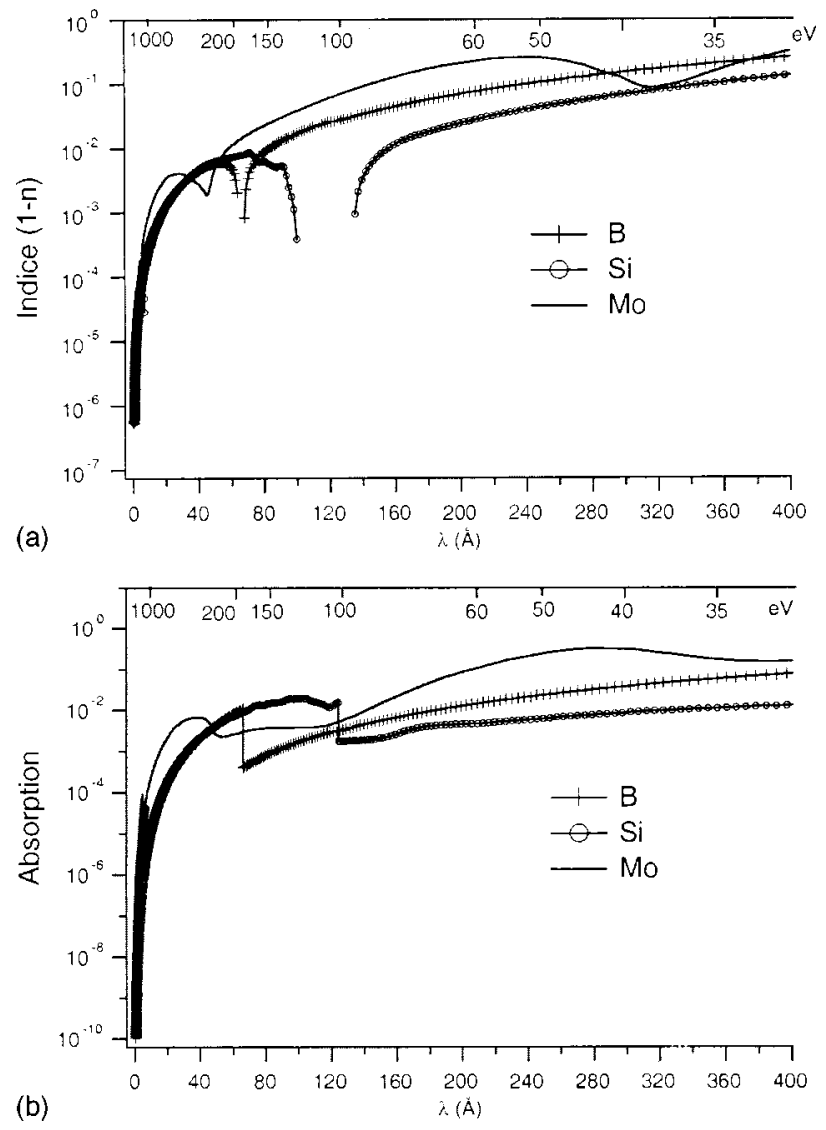

FIG. 1. (a) Indices (real part of $1-n$ ) of $\mathrm{Mo}, \mathrm{Si}$, and $\mathrm{B}$ computed from Henke table. (b) Absorption of $\mathrm{Mo}, \mathrm{Si}$, and $\mathrm{B}$ computed from Henke table.

multilayer with a $\gamma$ of 0.24 . For $\gamma$ equal to 0.24 , curves a and c of Fig. 2 exhibit the same peak reflectivity, but the curve related to $\mathrm{B} / \mathrm{Si}$ is narrower.

\section{INTEREST OF B/Si MULTILAYERS: POTENTIAL APPLICATIONS}

\section{A. Selectivity}

This property is needed for monochromator applications. For example, it can be used to select one of the discrete

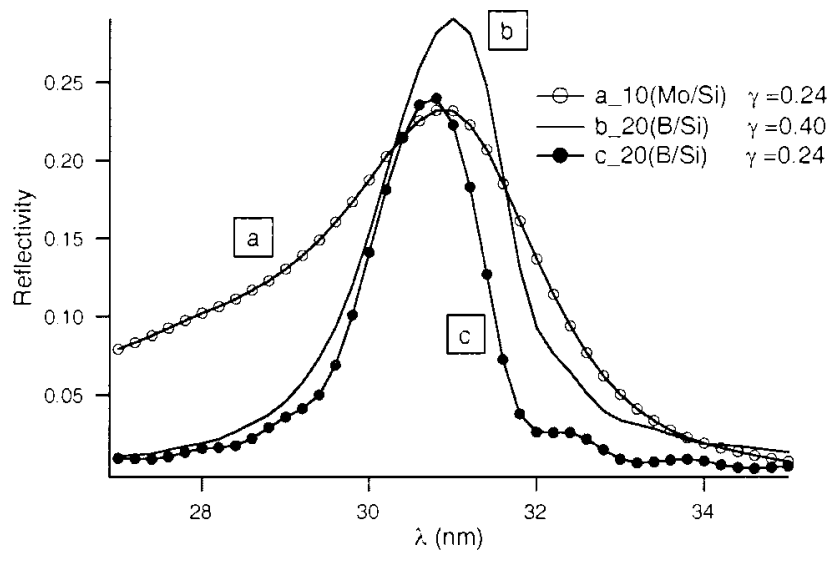

FIG. 2. Calculated reflectivity around $30.9 \mathrm{~nm}$ for three multilayers at normal incidence: (a) $\mathrm{Mo} / \mathrm{Si}$ with optimized reflectivity; (b) B/Si with optimized reflectivity; (c) $\mathrm{B} / \mathrm{Si}$ with optimized selectivity and same reflectivity as multilayer (a) 


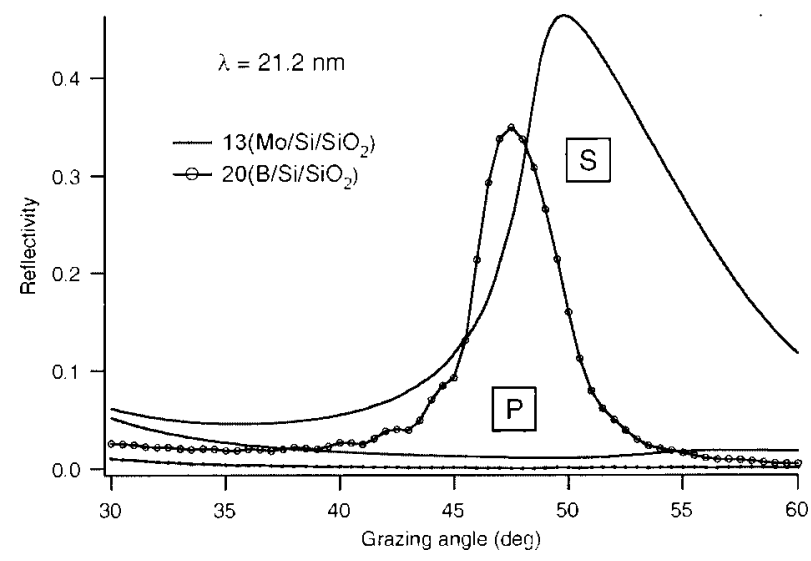

FIG. 3. Calculated reflectivity of $\mathrm{Mo} / \mathrm{Si}$ and $\mathrm{B} / \mathrm{Si}$ multilayers optimized for the $\mathrm{S}$ polarization at $21.2 \mathrm{~nm}$.

energies produced in the XUV range by high order harmonic generation sources. ${ }^{18}$ In this case, an infrared laser is used to illuminate a nonlinear absorption material. Each re-emitted wavelength can be calculated as the ratio of the fundamental wavelength $\lambda_{0}$ over the harmonic number $H_{n}$. But only the odd harmonics are present. For example, for $\lambda_{0}=795 \mathrm{~nm}$, the wavelength increment $\delta \lambda$ between $H_{21}$ and $H_{19}$ is: (795 $\mathrm{nm} / 19)-(795 \mathrm{~nm} / 21)=41.8 \mathrm{~nm}-37.9 \mathrm{~nm}=3.9 \mathrm{~nm}$. At $H_{21}$, for a $\gamma$ ratio of 0.2 , the band pass $\Delta \lambda$ related to the $\mathrm{Mo} / \mathrm{Si}$ multilayer is equal to $3.96 \mathrm{~nm}$ instead of $3.62 \mathrm{~nm}$ for $\mathrm{B} / \mathrm{Si}$. Therefore, B/Si multilayers will be preferred to $\mathrm{Mo} / \mathrm{Si}$ in order to select one of these two harmonics.

\section{B. Polarization power}

Figure 3 shows reflectivity curves of the Mo/Si and B/Si multilayers at $21.2 \mathrm{~nm}$, versus grazing incidence for $\mathrm{P}$ and $\mathrm{S}$ polarizations. The maximum of polarization is obtained when the $\mathrm{P}$ polarization, related to the electric field vector parallel to the incidence plane, is near zero. One can see that the B/Si multilayer leads to a lower reflectivity for the $\mathrm{P}$ polarization and a better selectivity for the $\mathrm{S}$ polarized wave. Polarization powers $R_{s} /\left(R_{p}+R_{s}\right)$ are also compared in Fig. 4.

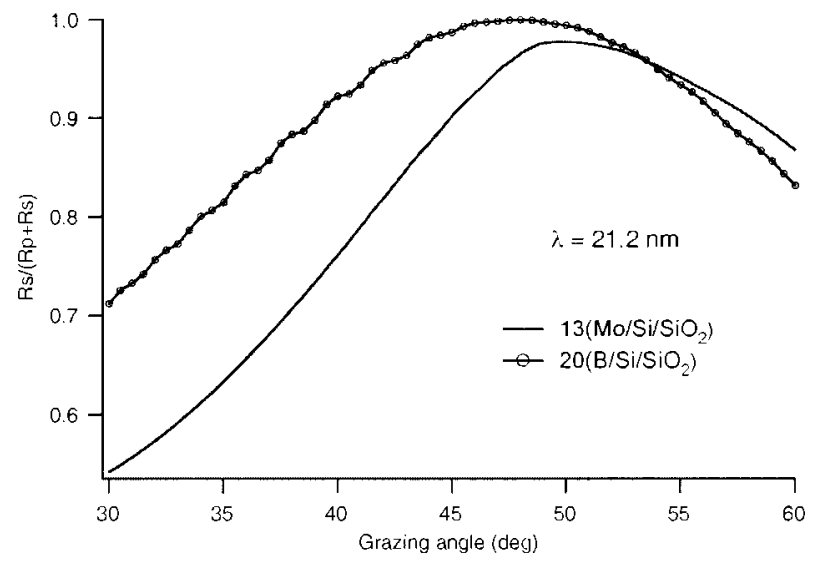

FIG. 4. Polarization power of the two multilayers of Fig. 4.

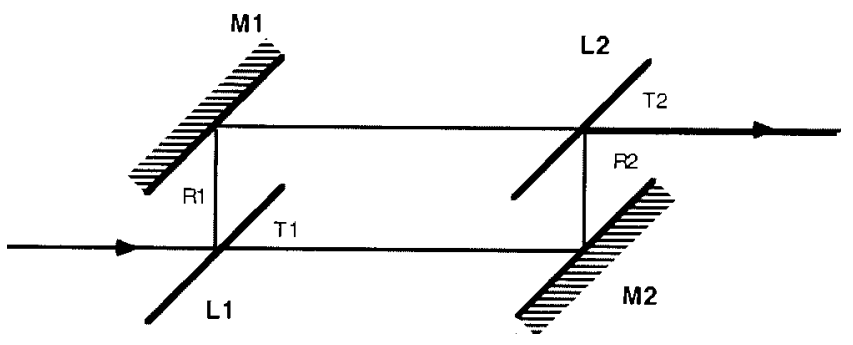

FIG. 5. Mach-Zender interferometer sketch with two thin multilayers $L 1$ and $L 2$ as beamsplitters and two mirrors $M 1$ and $M 2$.

\section{Low absorption beamsplitter}

Besides the reflectivity power, the low absorption multilayer is transparent for the XUV radiation, and can be used as a beamsplitter under oblique incidence in a MachZender interferometer for example (Fig. 5). Two thin beamsplitters are used in reflection and in transmission, and the product $R^{*} T$ has to be maximized. For an incident beam of $5^{\circ}$, Fig. 6 shows the calculated transmission and absorption coefficients of an optimized B/Si multilayer made of eleven periods on a first $10 \mathrm{~nm}$ Si layer which acts as a supporting film.

In order to obtain such beamsplitters, two techniques can be used. The first consists of the multilayer deposited onto a transparent supporting film like $\mathrm{Si}_{3} \mathrm{~N}_{4}$ or $\mathrm{SiC}$ membranes. ${ }^{19}$ However, the absorption of the supporting film may be a drawback in the range of very low energies. Another way consists of the multilayer deposited in a tensile mode onto a substrate which is etched afterward in order to obtain a flat multilayer free membrane. ${ }^{20}$

\section{FEASIBILITY OF B/Si MULTILAYERS}

\section{A. Choice of deposition techniques}

In our laboratory, multilayers can be deposited by two techniques: ion beam sputtering and electron beam evaporation. As it is well known that the thin films' stress depends strongly on the deposition conditions, we have done some experiments in order to determine the stress in $\mathrm{B} / \mathrm{Si}$ multilayers. We have deposited two batches of multilayers onto

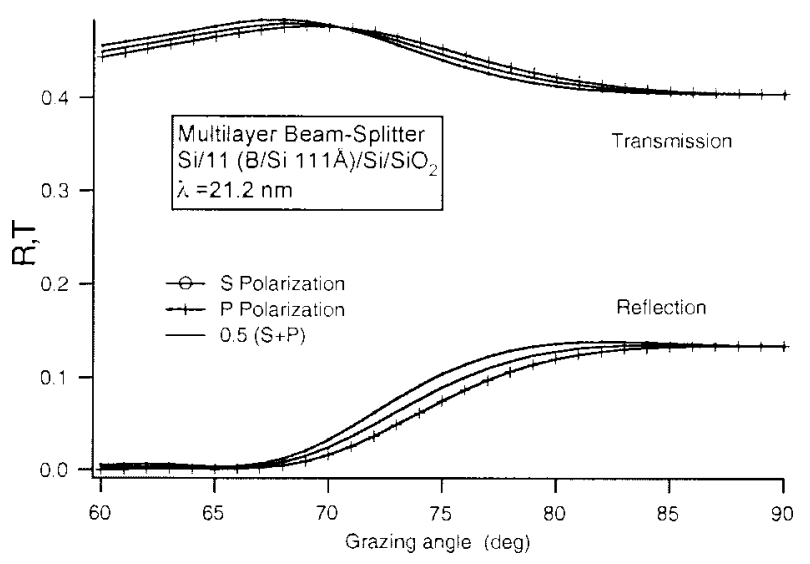

FIG. 6. Calcualted intensity of the reflected and transmitted wave on the beamsplitter at $21.2 \mathrm{~nm}$. The maximum of the product $R 1 . T 2=T 1 . R 2$ is required for an incidence of $85^{\circ}$ (incidence of $5^{\circ}$ ). 
silicon wafers. The first batch was obtained by ion beam sputtering with argon ions. The second was deposited by electron beam evaporation. In both cases, the substrate could be heated during the deposition. The stress of these samples was determined by interferometric measurements of the wafer curvature before and after the multilayer deposition, and by using the Stoney formulation. ${ }^{21}$ It is found that tensile stress is favored by using electron beam evaporation of both materials onto a heated substrate, whereas compressive stress takes place when ion-sputtering processes are used. For multilayers typically made with 15 periods of $11 \mathrm{~nm}$, the tensile stress was on the order of $+200 \mathrm{MPa}$ for evaporated multilayers and the compressive stress on the order of $-400 \mathrm{MPa}$ for ion sputtered multilayers.

Such a difference originates from microstructural and interfacial properties of the layers which are related to the energy of the particles arriving on the substrate during the deposition. Indeed, in ion sputtering techniques, the energy of the particles is on the order of $10 \mathrm{eV}$ (which induces displacements of the adatoms, and consequently the occurrence of interstitial defects), whereas, in the case of evaporation techniques, the energy is on the order of $0.5 \mathrm{eV}$.

The choice of the deposition technique has to take into account another factor which is the adhesion of the multilayer on the substrate. It appears that $\mathrm{B} / \mathrm{Si}$ multilayers deposited by evaporation show better adhesion properties than when they are deposited by ion beam sputtering. The goal of the study of $\mathrm{B} / \mathrm{Si}$ multilayers is their applications as beamsplitters for UV laser radiation experiments at $\lambda=21.2$ $\mathrm{nm}$. The technology which will be used to obtain semitransparent membranes with these deposited B/Si films consists of the fabrication of a self supported film by using a multistep process already developed for $\mathrm{x}$-ray $\mathrm{Mo} / \mathrm{Si}$ membranes and described elsewhere. ${ }^{20}$ Consequently, stress and adhesion factors are extremely important in order to obtain membranes with an excellent flatness and a good reproducibility. So we decided to choose the electron beam evaporation technique for the multilayer deposition.

\section{B. Deposition process}

The $\mathrm{B} / \mathrm{Si}$ multilayers are obtained by electron beam evaporation in an ultrahigh vacuum chamber with a residual pressure of $10^{-10}$ mbar. High purity boron and silicon are evaporated alternatively from two separate crucibles. The temperature of the substrate is maintained at $200{ }^{\circ} \mathrm{C}$ and the residual pressure is typically in the $10^{-7}$ mbar range during the deposition process.

Stacks of ten bilayers have been deposited onto 2 in. diam $\langle 100\rangle$ polished silicon wafers. The substrate was previously covered with a PECVD $\mathrm{Si}_{3} \mathrm{~N}_{4}$ (thickness: $20 \mathrm{~nm}$ ) sublayer which is used as a stopping layer for the $\mathrm{KOH}$ etching at the end of the membrane process. The aimed nominal period was $12 \mathrm{~nm}$ with expected thickness of boron and silicon layers of about 3 and $9 \mathrm{~nm}$, respectively. The evaporation rate was monitored with a quartz crystal microbalance sensitive to the deposited mass and was typically maintained at $0.1 \mathrm{~nm} / \mathrm{s}$ for silicon and $0.2 \mathrm{~nm} / \mathrm{s}$ for boron.

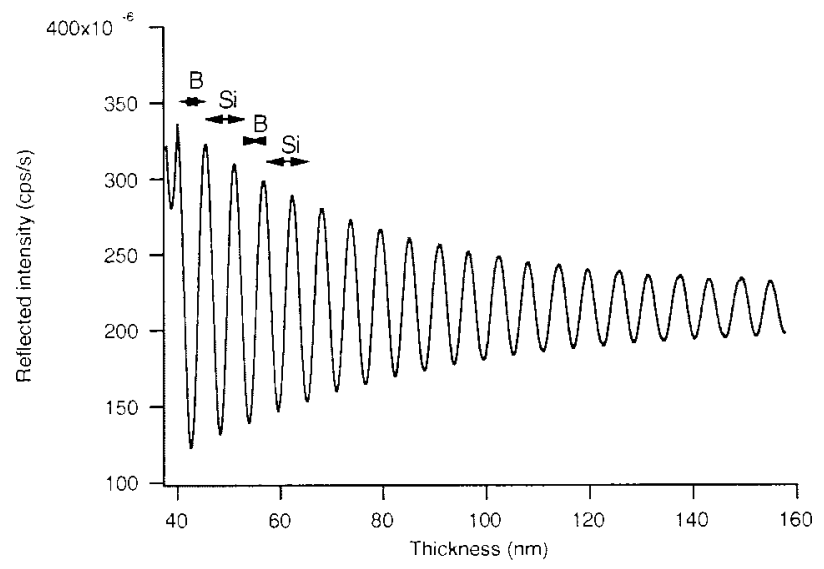

FIG. 7. In situ simulated reflectivity at $\lambda=4.47 \mathrm{~nm}$ vs thickness during the deposition of the $\mathrm{B} / \mathrm{Si}$ multilayer.

The reflectivity of the multilayers has been controlled during the deposition process by way of the in situ reflectometer working at $\lambda=4.47 \mathrm{~nm}$ (C $K \alpha$ line). This device fitted on our deposition chamber according to the design described by Spiller ${ }^{22}$ allows us to reach a good reproducibility of the multilayer period. ${ }^{14}$ The simulated curve of the specular reflectivity versus thickness of the stack during deposition is shown in Fig. 7.

\section{Reflectivity measurements}

The specular x-ray reflectivity was measured ex situ on the deposited multilayers for two wavelengths: 0.154 and $12.6 \mathrm{~nm}$. The relative reflectivity was measured as a function of the incident angle with a reflectometer working with the $\mathrm{Cu} K \alpha$ radiation $(\lambda=0.15405 \mathrm{~nm})$ delivered by a classical diffraction tube equipped with a graphite rear monochromator and $40 \mu \mathrm{m}$ entrance and reception slits. The resolution of the reflectometer is better than $0.001^{\circ}$.

In the soft x-ray region, the absolute reflectivity was measured as a function of the glancing angle at a fixed photon energy, and as a function of the photon energy at a fixed glancing angle. The measurements were carried out at the LURE synchrotron facility (Orsay) on the SA23 beamline of the Super-ACO storage ring. The line is equipped with a toroidal $15001 / \mathrm{mm}$ grating monochromator and a soft $\mathrm{x}$-ray reflectometer. The spectral resolution of the monochromator is around $1 \mathrm{eV}$ for a photon energy of $100 \mathrm{eV}$. The reflectometer consists of a $\theta-2 \theta$ goniometer with an angular resolution better than $0.1^{\circ}$ and a photodiode as a photon detector.

Measurements at a fixed photon energy of $98 \mathrm{eV}(\lambda$ $=12.6 \mathrm{~nm}$ ) versus the glancing angle were performed. Additional measurements of the reflectivity were achieved at a fixed glancing angle of $32.5^{\circ}$ as a function of the photon energy in the $90-110 \mathrm{eV}$ range. These experimental conditions were chosen by taking into account the geometrical limitations of the reflectometer.

Then, the reflection curves have been analyzed by using a multilayer computer program based on the Fresnel formalism and recursive computation procedures. ${ }^{23}$ The parameters involved in the fitting are: optical constants of each element as a function of photon energy (cf. Henke tabulation), and 


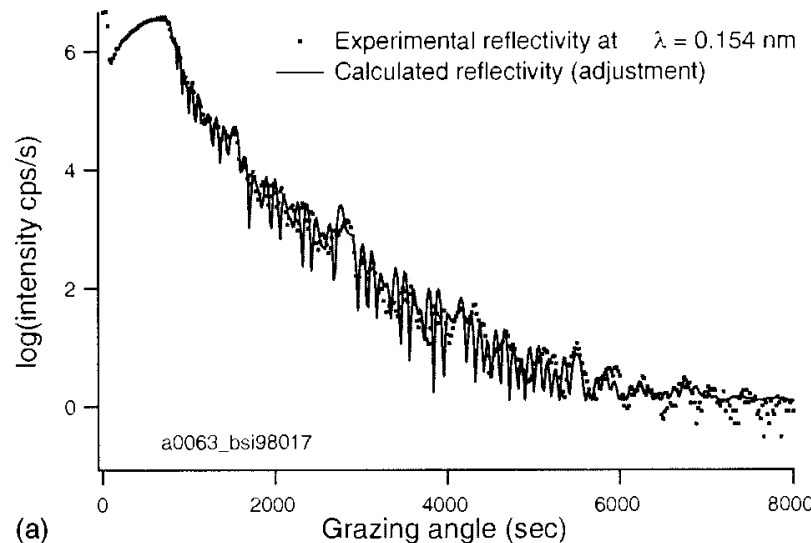

(a)

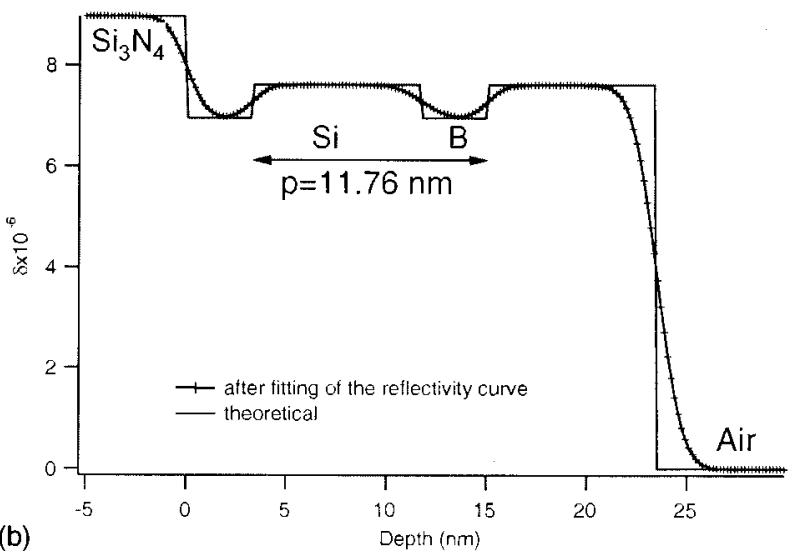

FIG. 8. (a) Measured and fitted reflectivity of B/Si multilayers versus grazing angle at $\lambda=0.154 \mathrm{~nm}$. (b) Simulated optical index profile at $\lambda=0.154$ $\mathrm{nm}$. The continuous line curve corresponds to theoretical parameters: bulk indices and perfect interfaces, the other curve is calculated from resulting parameters of the fit given in Table I.

thickness of layers and interfacial roughness. The roughness is treated as an additional interfacial layer according to the formalism given in Ref. 12.

The profiles of the optical index as a function of the multilayer depth have been deduced from the experimental reflectivity curves by using a calculation code described in Ref. 15.

\section{RESULTS AND DISCUSSION}

Experimental and fitted reflectivities versus the grazing angle for each wavelength $\lambda=0.154 \mathrm{~nm}$ and $\lambda=12.6 \mathrm{~nm}$ are reported on Figs. 8(a) and 9(a), respectively.

The quantitative parameters defining the multilayer deduced from the optimized fits are given in Tables I and II. The profiles of the optical index are reported in Figs. 8(b)

TABLE I. Parameters of the fit at $\lambda=0.154 \mathrm{~nm}$ (Fig. 8).

\begin{tabular}{lccccc}
\hline \hline Layer & $\mathrm{N}^{\circ}$ & $\begin{array}{c}\text { Thickness } \\
(\mathrm{nm})\end{array}$ & $\begin{array}{c}\text { Roughness } \\
(\mathrm{nm})\end{array}$ & $\begin{array}{c}\text { Indice } \\
\left(10^{-6}\right)\end{array}$ & $\begin{array}{c}\text { Absorption } \\
\left(10^{-6}\right)\end{array}$ \\
\hline Substrate & 0 & $\infty$ & 0.5 & 7.604 & 0.173 \\
$\mathrm{Si}_{3} \mathrm{~N}_{4}$ & 1 & 40 & 0.8 & 8.962 & 0.11 \\
$\mathrm{~B}$ & 2 & 3.2 & 0.7 & 6.951 & 0.006 \\
$\mathrm{Si}$ & 3 & 8.56 & 1 & 7.604 & 0.173 \\
$\mathrm{~B}$ & 22 & 32 & 1.13 & 6.951 & 0.006 \\
\hline \hline
\end{tabular}
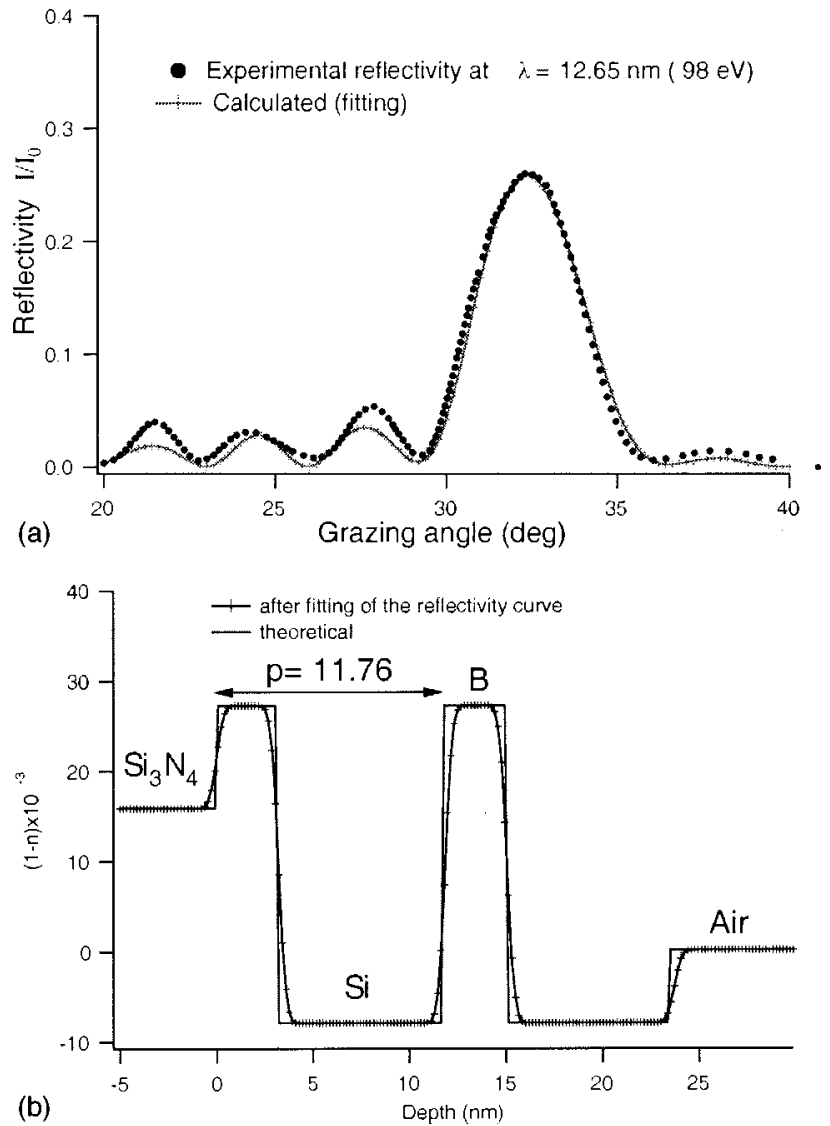

FIG. 9. (a) Measured and fitted reflectivity of B/Si multilayers versus grazing angle at $\lambda=12.6 \mathrm{~nm}$. (b) Parameters of fits and simulated optical index profile at $\lambda=12.6 \mathrm{~nm}$. The continuous line curve corresponds to theoretical parameters: bulk indices and perfect interfaces, the other curve is calculated from resulting parameters of the fit given in Table II.

and 9(b). The mean value of the layer thicknesses and consequently of the period of the multilayer, provided by the fits, are in good agreement for each wavelength within an accuracy range of $0.2 \mathrm{~nm}$. So the multilayer is effectively a stack of ten bilayers of $\mathrm{B}(3.3 \mathrm{~nm}) / \mathrm{Si}(8.5 \mathrm{~nm})$. We notice that the silicon and boron optical constants included in our calculations and reported from the Henke data are adequate to fit correctly the reflectivity at $\lambda=0.154 \mathrm{~nm}$ as well as at $\lambda=12.6 \mathrm{~nm}$. This allows us to conclude that silicon and boron deposited thin film are made of dense and pure materials.

In any case, an interfacial layer must be introduced in the calculations in order to fit the experimental data. This interfacial layer may be interpreted as an interfacial roughness or as an interdiffusional layer. The thickness of this

TABLE II. Parameters of the fit at $\lambda=12.6 \mathrm{~nm}$ (Fig. 9).

\begin{tabular}{lccccc}
\hline \hline Layer & $\mathrm{N}^{\circ}$ & $\begin{array}{c}\text { Thickness } \\
(\mathrm{nm})\end{array}$ & $\begin{array}{c}\text { Roughness } \\
(\mathrm{nm})\end{array}$ & $\begin{array}{c}\text { Indice } \\
\left(10^{-6}\right)\end{array}$ & $\begin{array}{c}\text { Absorption } \\
\left(10^{-6}\right)\end{array}$ \\
\hline Substrate & 0 & $\infty$ & 0.3 & -7980.14 & 1780.16 \\
$\mathrm{Si}_{3} \mathrm{~N}_{4}$ & 1 & 40 & 0.3 & 15869.2 & 7867.31 \\
$\mathrm{~B}$ & 2 & 3.2 & 0.3 & 27517.4 & 3323.3 \\
$\mathrm{Si}$ & 3 & 8.6 & 0.3 & -7980.14 & 1780.16 \\
$\mathrm{~B}$ & 4 & & 0.3 & 27517.4 & 3323.3 \\
\hline \hline
\end{tabular}




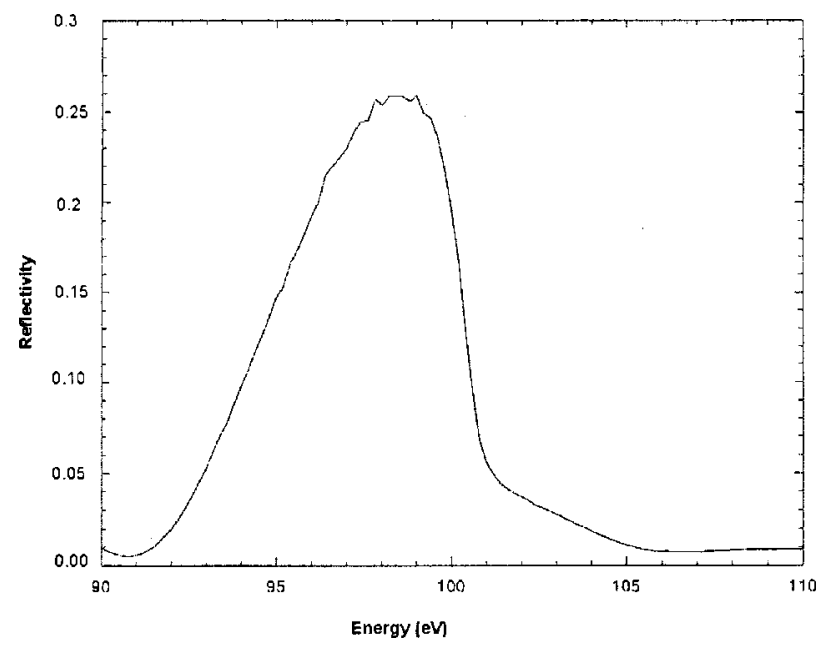

FIG. 10. Measured absolute reflectivity of $\mathrm{B} / \mathrm{Si}$ multilayers vs the photon energy for a glancing angle of $32.6^{\circ}$.

layer ranges between 0.3 and $0.7 \mathrm{~nm}$ depending on the wavelength. The analysis of the reflectivity curve is not easy at the wavelength of $0.15405 \mathrm{~nm}$ because of the low contrast between the optical indices of B and $\mathrm{Si}$ in this region. Then the value obtained for the interfacial layers thickness is not so accurate at this wavelength. However, our results are in good agreement with the upper limit of $0.98 \mathrm{~nm}$ of the interfacial diffusion of Si into B found by Kearney et al. ${ }^{10}$

The maximum reflectivity and the resolution of the $\mathrm{B} / \mathrm{Si}$ multilayers can be estimated from the experimental curve of the reflectivity plotted versus the photon energy at a glancing angle of $32.6^{\circ}$ (Fig. 4). So, for the stack of ten bilayers B(3.3 $\mathrm{nm}) / \mathrm{Si}(8.5 \mathrm{~nm})$, at $98 \mathrm{eV}$, the maximum reflectivity is $25 \%$ with a band pass of $5.7 \mathrm{eV}$ (see Fig. 10).

\section{CONCLUSIONS}

$\mathrm{B} / \mathrm{Si}$ multilayer mirrors offer promising properties in the soft $\mathrm{X}$-ray and XUV energy range although they have been unexplored up until now. This work constitutes an approach of the feasibility and the properties of such layers in view of their applications for optics used with $\mathrm{x}$-ray sources and in the astrophysics field. Some evidence is shown that components of the $\mathrm{B} / \mathrm{Si}$ multilayers deposited by electron gun evaporation have refraction indices close to the theoretical values. This suggests that the density of the layers could be very close to the bulk materials. However, an interfacial layer must be introduced to fit the experimental reflectivity curves in any case. The rather low value of roughness suggests that a sharp interface is formed between $\mathrm{Si}$ and $\mathrm{B}$. Further experiments have to be performed on B/Si multilayers deposited by us in order to characterize the quality of the interfaces. So, microstructural investigations by high resolution transmission electron microscopy and nuclear reaction analysis are under progress.
Complementary experiments will be done on $\mathrm{B} / \mathrm{Si}$ multilayers to understand more precisely the mechanisms involved in the structural evolution of the layers and the microstructure of the interfaces. In addition, quantitative determinations of stress in $\mathrm{B} / \mathrm{Si}$ from interferometric experiments will be achieved.

This work will be continued to obtain narrow band pass mirrors, low absorption monochromators, and beamsplitters based on $\mathrm{B} / \mathrm{Si}$ multilayers for XUV photon energy ranges. In order to characterize such optical devices, the reflectivity of the multilayers will be studied for higher photon wavelengths $(20-30 \mathrm{~nm})$ provided by synchrotron radiation facilities.

\section{ACKNOWLEDGMENTS}

The authors would like to thank P. Troussel from the Commissariat à l'Energie Atomique CEA/DRIF/DCREBruyères le Châtel for access to the reflectometer of the SA23 beam line at LURE-Orsay, and also for his fruitful comments about this article.

${ }^{1}$ G. A. Kryala and J. C. Gauthier, Proc. SPIE 357 (1997).

${ }^{2}$ A. L'Huillier and Ph. Balcou, Phys. Rev. Lett. 70, 774 (1993).

${ }^{3}$ P. Jaegle and A. Sureau, J. Phys. Colloq. C6, 47 (1986).

${ }^{4}$ P. Jaeglé, A. Carillon, P. Dhez, P. Goettkindt, G. Jamelot, A. Klisnick, B. Rus, and Ph. Zeitoun, AIP Conf. Proc. 332, 25 (1995).

${ }^{5}$ J.-P. Delaboudiniere, J.-F. Hochedez, J.-P. Chauvineau, and L. Valiergue, Proc. SPIE 1742, 296 (1992).

${ }^{6}$ E. Spiller, Soft X-Ray Optics (SPIE Optical Engineering, Bellingham, WA, 1994).

${ }^{7}$ J.-A. Folta et al., Proc. SPIE 3676, 1 (1998)

${ }^{8}$ J.-P. Delaboudinière, T. K. Vien, and J.-P. Chauvineau, Proc. SPIE 1160, 261 (1989).

${ }^{9}$ B. L. Henke, E. M. Gullikson, and J. C. Davis, At. Data Nucl. Data Tables 54, 181 (1993).

${ }^{10}$ P. Kearney, J. M. Slaughter, and C. Falco, Proc. SPIE 1547, 63 (1991).

${ }^{11}$ C. Hombourger, P. Jonnard, J.-M. André, and J.-P. Chauvineau, X-Ray Spectrom. 28, 10 (1999).

${ }^{12}$ B. Pardo, T. Megademini, and J. M. André, Rev. Phys. Appl. 23, 1579 (1988).

${ }^{13}$ L. G. Parrat, Phys. Rev. 95, 359 (1954).

${ }^{14}$ E. Spiller, Opt. Eng. (Bellingham) 25, 954 (1986).

${ }^{15}$ L. Névot and P. Croce, Rev. Phys. Appl. 15, 761 (1980).

${ }^{16}$ L. Névot, B. Pardo, and J. Corno, Rev. Phys. Appl. 23, 1675 (1988).

${ }^{17}$ J. P. Delaboudinière et al., Extreme-ultraviolet imaging telescope for the Soho mission. Sol. Phys. 162, 291 (1995).

${ }^{18}$ L. Le Déroff, P. Salières, and B. Carré, Opt. Lett. 23, 1544 (1988).

${ }^{19}$ T. Haga, M. C. K. Tinone, A. Ozawa, Y. Utsumi, S. Itabashi, T. Ohkubo, and M. Shimada, Proc. SPIE 3764, 13 (1999).

${ }^{20}$ C. Kahn Malek, J. Susini, A. Madouri, M. Ouahabi, R. Rivoira, F. R. Ladan, Y. Lepêtre, and R. Barchewitz, Opt. Eng. (Bellingham) 29, 597 (1990).

${ }^{21}$ G. G. Stoney, Proc. R. Soc. London, Ser. A 82, 172 (1909).

${ }^{22}$ E. Spiller, Evaporated Multilayer Dispersion Elements for Soft X-Rays, in Low Energy X-ray diagnostics, edited by D. T. Attwood and B. L. Henke (American Institute of Physics, Woodbury, NY, 1981).

${ }^{23}$ F. Bridou and B. Pardo, J. Opt. 21, 183 (1990). 